\title{
Oncogene addiction and immune escape: friends or foes?
}

\author{
Pamela Abdayem, David Planchard \\ Department of Medical Oncology, Gustave Roussy, Villejuif, France \\ Correspondence to: David Planchard, MD. Department of Medical Oncology, Gustave Roussy, 114 Edouard Vaillant Street, 94805 Villejuif Cedex, \\ France. Email: david.planchard@gustaveroussy.fr. \\ Comment on: Brown H, Vansteenkiste J, Nakagawa K, et al. Programmed Cell Death Ligand 1 Expression in Untreated EGFR Mutated Advanced \\ NSCLC and Response to Osimertinib Versus Comparator in FLAURA. J Thorac Oncol 2020;15:138-43.
}

Submitted Mar 31, 2020. Accepted for publication Apr 17, 2020.

doi: $10.21037 /$ atm-20-3036

View this article at: http://dx.doi.org/10.21037/atm-20-3036

Epidermal growth factor receptor (EGFR) is an oncogenic driver that activates three downstream main signaling pathways, namely mitogen-activated protein kinases (MAPK)/extracellular signal-regulated kinases (ERK), phosphatidylinositol 3-kinase (PI3K)/protein kinase B $(\mathrm{AKT}) / \mathrm{mammalian}$ target of rapamycin (mTOR), and interleukin 6 (IL-6)/Janus kinase (JAK)/signal transducer and activator of transcription 3 (STAT3) (1). Prognosis was dramatically improved in patients with advanced non-small cell lung cancer (NSCLC) harboring somatic activating EGFR mutations (EGFRm) who were treated with EGFR tyrosine kinase inhibitors (EGFR-TKIs) $(2,3)$. Recently, in the FLAURA phase III study, EGFRm-positive patients with untreated advanced NSCLC who received osimertinib, a third-generation irreversible EGFR-TKI that selectively inhibits both EGFR-TKI-sensitizing and EGFR T790M resistance mutations, achieved a progression-free survival (PFS) and overall survival (OS) of 18.9 and 38.6 months, respectively, in comparison with gefitinib or erlotinib (4-6). However, progression is inevitable and immune checkpoint inhibitors (ICIs) have not achieved satisfactory outcomes after treatment with EGFR-TKIs. Palliative platinum-based chemotherapy remains the treatment backbone of progressive EGFR-mutated disease. Increased levels of vascular endothelial growth factor (VEGF) were found in NSCLC cell lines with EGFR mutation, thus suggesting a significant role of EGFR activation in tumor angiogenesis and an increased sensitivity to bevacizumab (7). A recent key subgroup analysis of patients with EGFR sensitizing mutations treated in the Impower 150 phase 3 study of atezolizumab plus bevacizumab and chemotherapy versus bevacizumab and chemotherapy, showed promising results (8). The interplay between the EGFR oncogenic pathway and immune escape mechanisms is poorly understood. Solid evidence is yet to be found.

Brown et al. recently tested 197 patient formalin-fixed paraffin-embedded blocks with sufficient tissue available from the screened population in the FLAURA trial (231 tissue blocks initially available) for programmed-death ligand 1 (PD-L1) expression. They used the VENTANA PD-L1 (SP263) immunohistochemical assay for tumor cell (TC) scoring. They also performed immune cell (IC) scoring incorporated into the VENTANA PD-L1 (SP142) assay, as part of an exploratory analysis. Three TC and IC staining thresholds were selected: 1\%, 25\% and $50 \%$. Results were recently published in the fournal of Thoracic Oncology. Compared to EGFRm-negative patients, EGFRm-positive patients expressed PD-L1 less often and the difference was more prominent at higher PD-L1 TC thresholds ( $51 \%$ vs. $68 \%$ at a TC $\geq 1 \%, 8 \%$ vs. $35 \%$ at TC $\geq 25 \%$ and $5 \%$ vs. $28 \%$ at TC $\geq 50 \%)$. Among the 106 of 128 EGFRm-positive patients randomized in FLAURA (54, osimertinib; 52, comparator), 52 (49\%), 8 (8\%) and 5 (5\%) had a PD-L1 greater than or equal to $1 \%, 25 \%$ and $50 \%$, respectively. $\mathrm{PFS}$ (at $\mathrm{TC} \geq 1 \%$ and $\mathrm{IC} \geq 1 \%$ ) and response rates (RR) (at $\mathrm{TC} \geq 1 \%$ ) to osimertinib were similar in the two PD-L1 subgroups and were in alignment with the median PFS (18.9 months) and RR (80\%) to osimertinib for the overall FLAURA population (9).

In this FLAURA trial, PD-L1 expression was higher in EGFRm-negative tumor samples. Since the expression of PD-L1 was among the exploratory endpoints in the FLAURA trial, the number of patients with tissue samples that were evaluable for PD-L1 testing was limited. Results 
should therefore be interpreted with caution. The crosstalk between the EGFR oncogene and PD-L1 expression remains controversial, with conflicting data emerging from preclinical versus epidemiological studies. Preclinical data suggested an additional role for the EGFR oncogene, besides cell proliferation and survival, in remodeling the immune microenvironment. The tumor microenvironment of mice with EGFRm-positive tumors was found to have higher levels of immunosuppressive cytokines (IL-6, TGF- $\beta$ ), PD-L1 and Foxp3 as well as lower CD8+/CD4+ and CD8+/Foxp3+ proportions (10). A higher expression of PD-L1, PD-L2 and CTLA-4 was reported in T790M/ L858R mouse tumors using microarray expression (10). Ectopic expression of mutated EGFR (and not KRASG12V expression) in immortalized bronchial epithelial cells increased PD-L1 levels (10). Through upregulation of the PD-1/PD-L1 pathway resulting in T cell exhaustion and rise of Foxp3+ regulatory T cells, EGFR-driven tumors succeeded in evading the immune system (10). Conversely, compared to EGFRm-negative tumors, EGFRm-positive tumors were $41 \%$ less likely to express PD-L1 in a pooled analysis of 18 studies with 3,969 patients (odds ratio $=0.59$; 95\% CI: 0.38-0.92; P<0.02) (11). Other clinical studies also corroborated these results $(12,13)$. The heterogeneity between studies might result from the difference in PDL1 testing methods (immunohistochemistry assays versus mRNA or protein expression), type of cells used for scoring (ICs vs. TCs) and applied thresholds. In accordance with the preclinical data mentioned above regarding the upregulation of PD-L1 expression on TC membranes PDL1 staining that uses TC scoring may appear intensified compared with other techniques using TC and IC scoring. In addition, PD-L1 expression levels might differ between tumor sites for the same individual and might change with time and drug exposure $(9,10,13,14)$. The current knowledge of the association between EGFR and PDL1 is therefore insufficient and often contradictory; more homogeneous studies are needed.

In a multicenter, retrospective study, $\mathrm{Ng}$ et al. analyzed 189 oncogene-driven (including KRAS) NSCLC patients among which 108 had a known PD-L1 status. PD-L1 expression $(\geq 1 \%)$ was more frequent in smokers $(\mathrm{P}=0.006)$, non-Asians $(\mathrm{P}=0.002)$ as well as KRAS mutation carriers $(\mathrm{P}=0.031)$ (14). In the FLAURA trial, The PD-L1 expressor (TC $\geq 1 \%$ ) subgroup had numerically more patients of Asian ethnicity, L858 R mutations, central nervous system and visceral metastases, whereas the PD-L1 non-expressor subgroup had more females, exon 19 deletions as well as patients of white ethnicity. While numerical differences exist between the characteristics of PD-L1 expressors versus non-expressors, a multi-adjusted analysis is necessary to identify which EGFRm-positive patient population may be more prone to express PD-L1.

The main message behind Brown et al.'s study is that PD-L1 expression does not seem to affect the benefit of EGFRm-positive patients with advanced NSCLC when treated with osimertinib, despite the small size of this subpopulation. Furthermore, mPFS with Osimertinib was very similar among the different PD-L1 subgroups, and to the mPFS of osimertinib for the overall FLAURA study population.

The bond between PD-L1 expression levels and response to EGFR TKIs in patients with EGFRm-positive advanced NSCLC remains unclear (11). The literature of the main studies focusing on the efficacy of EGFR TKIs in EGFRdriven tumors according to PD-L1 status is very inconsistent (summary in Table 1). The discordant results may be due to different factors, including differences in previous treatments received, $\mathrm{PD}-\mathrm{L} 1$ testing assays, $\mathrm{PD}-\mathrm{L} 1$ status analysis on fresh or archived tumor tissue, biopsy site, and scoring threshold cutoffs. Brown et al. reported a shorter mPFS in PD-L1 positive patients treated with gefitinib or erlotinib versus that of the comparator arm in the overall FLAURA population (6.9 vs. 10.2 months). These results match those of three other studies that reported decreased RR and shortened survival in PD-L1 positive EGFRm-positive patients treated with first and second- generation EGFR TKIs $(18,19,21)$. Since the previous studies did not include osimertinib, it can be assumed that a third generation EGFR TKI might overcome the negative prognostic impact of PDL1 expression in EGFRm-positive tumors. This needs to be confirmed in additional studies. Moreover, since results from the final analysis of OS in the FLAURA trial have been reported, an additional evaluation of OS in both treatment arms according to PD-L1 expression is warranted (4).

Patients with actionable driver mutations including EGFR are generally refractory to immunotherapy. Regardless of PD-L1 status, checkpoint inhibitors should only be used after progression on targeted therapies and probably all other available options including classic chemotherapy. A phase II trial of Pembrolizumab in TKInaïve EGFRm-positive patients was closed to further enrollment based on futility. No objective responses were achieved in $10 \mathrm{PD}-\mathrm{L} 1$ positive, EGFRm-positive patients including 7 with a PD-L1 expression $\geq 50 \%$ (16). Furthermore, after initiating subsequent EGFR TKIs 
Table 1 Impact of PD-L1 expression (before treatment) on sensitivity to EGFR TKIs in advanced EGFRm -positive NSCLC

\begin{tabular}{|c|c|c|c|c|}
\hline Author (year) & Study design & Number of patients & PD-L1 assessment method & Results \\
\hline $\operatorname{Lin}^{\ddagger}(2015)$ & $\begin{array}{l}\text { Retrospective; } \\
\text { single center }\end{array}$ & $\begin{array}{l}56 \text { EGFRm-positive } \\
\text { treated with gefitinib } \\
\text { or erlotinib }\end{array}$ & $\begin{array}{l}\text { IHC; TC and IC; cut-off } \\
=\text { mean } \mathrm{H} \text {-score from all } \\
\text { patients }\end{array}$ & $\begin{array}{l}\text { PD-L1 positive }(53.6 \%) \text { : higher DCR }(P=0.004) \text {, PFS } \\
(P=0.001) \text { and } O S(P=0.004)\end{array}$ \\
\hline $\operatorname{Tang}^{\S}(2015)$ & $\begin{array}{l}\text { Retrospective; } \\
\text { single center }\end{array}$ & $\begin{array}{l}170 \text { with NSCLC } \\
\text { treated with EGFR TKIs; } \\
99 \text { EGFRm-positive; } \\
71 \text { EGFR wild type }\end{array}$ & IHC & $\begin{array}{l}\text { PD-L1 expression more frequent in EGFRm-positive } \\
\text { patients ( } 71.9 \% \text { vs. } 57.1 \%, P=0.067) \text {; EGFRm-positive } \\
\text { and high PD-L1: no impact on OS ( } P=0.932) \text {; EGFR } \\
\text { wild type and high PD-L1: shorter OS }(P=0.029)\end{array}$ \\
\hline Soo" (2017) & $\begin{array}{l}\text { Retrospective; } \\
\text { single center }\end{array}$ & $\begin{array}{l}90 \text { patients, EGFR } \\
\text { m-positive (first line } \\
\text { EGFR TKIs) }\end{array}$ & $\begin{array}{l}\text { IHC; TC and IC; cut-off } \\
\geq 1 \% \text {; tumor } \mathrm{H} \text {-score }\end{array}$ & $\begin{array}{l}\text { High PD-L1 tumor H-score: shorter PFS (HR } 3.805 \text {, } \\
\mathrm{P}=0.022)\end{array}$ \\
\hline Cho $^{\Sigma}(2018)$ & $\begin{array}{l}\text { Retrospective; } \\
\text { single center }\end{array}$ & $\begin{array}{l}319 \text { EGFRm-positive } \\
\text { patients treated with } \\
\text { surgery; } 108 \text { patients } \\
\text { received TKls post } \\
\text { recurrence }\end{array}$ & $\begin{array}{l}\text { IHC; TPS }<1 \% \text { (negative), } \\
1-49 \% \text { and } \geq 50 \%\end{array}$ & $\begin{array}{l}\text { TPS } \geq 50 \% \text { vs. TPS }<1 \% \text { ( } 319 \text { EGFRm-positive } \\
\text { patients): shorter OS in the crude analysis HR } 2.7 \\
\text { (95\% CI, } 1.07 \text { to } 6.66 \text { ); difference non-significant after } \\
\text { adjusting for baseline prognostic factors and } \\
\text { chemotherapy, radiotherapy and EGFR TKI therapy }\end{array}$ \\
\hline $\begin{array}{l}\text { Matsumoto } \\
(2019)\end{array}$ & $\begin{array}{l}\text { Retrospective; } \\
\text { single center }\end{array}$ & $\begin{array}{l}70 \text { EGFRm-patients } \\
\text { (first line EGFR TKIs) }\end{array}$ & $\begin{array}{l}\text { IHC; TPS high } \geq 50 \% \\
\text { or low }<50 \%\end{array}$ & $\begin{array}{l}\text { RR lowest in type } 1(P=0.0085), P F S \text { shortest in type } 1 \\
\text { and longest in type } 4(P=0.00000077)\end{array}$ \\
\hline
\end{tabular}

\footnotetext{
†, 29 KRAS mutations, 10 ALK translocations and 30 EGFR/KRAS/ALK wild type (15); ${ }^{\ddagger}$, Semiquantitative $\mathrm{H}$ score = Staining score (0-3) $\times$ Proportion score (0-3). PD-L1 expression was not significantly influenced by either TILs or clinicopathologic features (16); ${ }^{\S}$, (17) few studies directly focus on the association between epidermal growth factor receptor (EGFR); ", (18); ${ }^{*}$, PD-L1 predominantly expressed in patients with primary resistance rather than acquired resistance to EGFR-TKIs $(66.7 \%$ vs. $30.2 \%, P=0.009)(19) ;{ }^{\Sigma}$, this study included patients with early stage EGFR mutant NSCLC. 108 patients received TKIs at recurrence. Higher frequency of PD-L1 positivity among men, smokers, patients with metastatic disease and those with other EGFR mutations than L858R or exon 19 deletion (20); ${ }^{\epsilon}$, four types of microenvironment based on PD-L1 and CD8+ Tumor infiltrating lymphocytes (TILs) expression: type 1 PD-L1 high/CD8+ high, type 2 PD-L1 low/CD8+ low, type 3 PD-L1 high/CD8+ low, type 4 PD-L1 low/CD8+ high (21). NSCLC, non-small cell lung cancer; TKls, tyrosine kinase receptors; EGFR, epidermal growth factor receptor; IHC, immunohistochemistry, RR, response rates; PFS, progression-free survival; RFS, relapse-free survival; OS, overall survival; TPS, tumor proportion score; TC, tumor cell scoring; IC, immune cell scoring; $\mathrm{DCR}$, disease control rate; $\mathrm{Cl}$, confidence interval; $\mathrm{HR}$, hazard ratio.
}

(7 patients), a patient developed grade 3 transaminitis and another died of grade 5 pneumonitis 89 days after starting erlotinib and 132 days after the last cycle of Pembrolizumab, thus raising significant concern about this sequence of therapies (22). We need to learn which EGFRm positive patients would most likely benefit from the use of immune checkpoint inhibitors, how to identify them, which treatment sequence is best and how to manage the subsequent toxicities that they might experience. There are two ways to enhance the efficacy of immunotherapy in tumors with EGFR oncogenic addiction. The first is to combine immunotherapy with other therapies such as standard cytotoxic chemotherapy and/or antiangiogenic drugs. Promising results with the combination of atezolizumab, bevacizumab and chemotherapy in patients with EGFR mutations were recently published (8). Indeed, EGFR signaling has been shown to promote VEGF expression in tumors thus possibly enhancing the sensitivity to bevacizumab in patients with EGFR mutations (7). The second way is to identify new pertinent biomarkers 
in addition to $\mathrm{PD}-\mathrm{L} 1$ expression and tumor mutational burden (TMB). A lower TMB and an immunosuppressive tumor microenvironment may partially explain the lower sensitivity to immune checkpoint inhibitors in EGFRmpositive patients. Moreover, EGFR TKIs were found to have both immunostimulatory and immunosuppressive effects. Treatment with EGFR TKIs downregulates PD-L1 expression, enhances peripheral natural killer cell activity, increases interferon gamma which is involved in immune surveillance and reduces levels of IL-6 which promotes tumorigenesis (7,17-19). In opposite, EGFR TKIs may inhibit T-cell proliferation/activation while increasing myeloid derived suppressor cells that are generally associated with tumor progression (20,21). Since activation of the EGFR pathway upregulates PD-L1, it may increase sensitivity to PD-1 blockade. Therefore, combining antiPD1 therapy with EGFR TKIs may be an interesting solution to prevent development of resistance and prolong treatment response (7). An important limitation of the FLAURA trial is that it only looked at the expression of PD-L1 without other biomarkers, and tumor mutational burden was not recorded (9).

The current data support the prioritization of EGFR targeting therapies in EGFR driven tumors regardless of PD-L1 status. We will never cease to accentuate the importance of molecular screening before PD-L1 expression assessment, especially in low or never-smoker patients, and that EGFR mutation and PD-L1 expression are not exclusive. Let us not get caught up in the whirlwind of false friends (PD-L1 status and immune checkpoint inhibitors) when EGFR and osimertinib are best friends.

\section{Acknowledgments}

Funding: None.

\section{Footnote}

Provenance and Peer Review: This article was commissioned and reviewed by the Section Editor Kaiping Zhang, $\mathrm{PhD}$ (AME College, AME Group, China).

Conflicts of Interest: Both authors have completed the ICMJE uniform disclosure form (available at http://dx.doi. org/10.21037/atm-20-3036). PA reports non-financial support from Pierre Fabre, non-financial support from Roche, outside the submitted work; DP reports personal fees, non-financial support and other from AstraZeneca, personal fees and other from Bristol-Myers Squibb, personal fees and other from Boehringer Ingelheim, personal fees from Celgene, personal fees and other from Daiichi Sankyo, personal fees and other from Eli Lilly, personal fees and other from Merck, personal fees, non-financial support and other from Novartis, personal fees, non-financial support and other from Pfizer, personal fees and non-financial support from Prime Oncology, personal fees from Peer CME, personal fees, non-financial support and other from Roche, other from Medimmun, other from Sanofi-Aventis, other from Taiho pharma, other from Novocure, outside the submitted work.

Ethical Statement: The authors are accountable for all aspects of the work in ensuring that questions related to the accuracy or integrity of any part of the work are appropriately investigated and resolved.

Open Access Statement: This is an Open Access article distributed in accordance with the Creative Commons Attribution-NonCommercial-NoDerivs 4.0 International License (CC BY-NC-ND 4.0), which permits the noncommercial replication and distribution of the article with the strict proviso that no changes or edits are made and the original work is properly cited (including links to both the formal publication through the relevant DOI and the license). See: https://creativecommons.org/licenses/by-nc-nd/4.0/.

\section{References}

1. Hsu PC, Jablons DM, Yang CT, et al. Epidermal Growth Factor Receptor (EGFR) Pathway, Yes-Associated Protein (YAP) and the Regulation of Programmed Death-Ligand 1 (PD-L1) in Non-Small Cell Lung Cancer (NSCLC). Int J Mol Sci 2019. doi: 10.3390/ijms20153821.

2. Mok TS, Wu YL, Thongprasert S, et al. Gefitinib or Carboplatin-Paclitaxel in Pulmonary Adenocarcinoma. N Engl J Med 2009;361:947-57.

3. Zhou C, Wu YL, Chen G, et al. Erlotinib versus chemotherapy as first-line treatment for patients with advanced EGFR mutation-positive non-small-cell lung cancer (OPTIMAL, CTONG-0802): a multicentre, open-label, randomised, phase 3 study. Lancet Oncol 2011;12:735-42.

4. Ramalingam SS, Vansteenkiste J, Planchard D, et al. Overall Survival with Osimertinib in Untreated, EGFR-Mutated Advanced NSCLC. N Engl J Med 2020;382:41-50. 
5. Soria JC, Ohe Y, Vansteenkiste J, et al. Osimertinib in Untreated EGFR-Mutated Advanced Non-Small-Cell Lung Cancer. N Engl J Med 2018;378:113-25.

6. Decoster L, Giron P, Mignon S, et al. The evolving firstline treatment of advanced non-small cell lung cancer harbouring epidermal growth factor receptor mutations. Transl Lung Cancer Res 2018;7:S134-7.

7. Hung MS, Chen IC, Lin PY, et al. Epidermal growth factor receptor mutation enhances expression of vascular endothelial growth factor in lung cancer. Oncol Lett 2016;12:4598-604.

8. Reck M, Mok TSK, Nishio M, et al. Atezolizumab plus bevacizumab and chemotherapy in non-small-cell lung cancer (IMpower150): key subgroup analyses of patients with EGFR mutations or baseline liver metastases in a randomised, open-label phase 3 trial. Lancet Respir Med 2019;7:387-401.

9. Brown H, Vansteenkiste J, Nakagawa K, et al. Programmed Cell Death Ligand 1 Expression in Untreated EGFR Mutated Advanced NSCLC and Response to Osimertinib Versus Comparator in FLAURA. J Thorac Oncol 2020;15:138-43.

10. Akbay EA, Koyama S, Carretero J, et al. Activation of the PD-1 pathway contributes to immune escape in EGFRdriven lung tumors. Cancer Discov 2013;3:1355-63.

11. Soo RA, Lim SM, Syn NL, et al. Immune checkpoint inhibitors in epidermal growth factor receptor mutant non-small cell lung cancer: Current controversies and future directions. Lung Cancer 2018;115:12-20.

12. Dong ZY, Zhang JT, Liu SY, et al. EGFR mutation correlates with uninflamed phenotype and weak immunogenicity, causing impaired response to PD-1 blockade in non-small cell lung cancer. OncoImmunology 2017;6:e1356145.

13. Zhang M, Li G, Wang Y, et al. PD-L1 expression in lung cancer and its correlation with driver mutations: a metaanalysis. Sci Rep 2017;7:10255.

14. Ng TL, Liu Y, Dimou A, et al. Predictive value of

Cite this article as: Abdayem P, Planchard D. Oncogene addiction and immune escape: friends or foes? Ann Transl Med 2020;8(18):1194. doi: 10.21037/atm-20-3036 oncogenic driver subtype, programmed death-1 ligand (PD-L1) score, and smoking status on the efficacy of PD-1/PD-L1 inhibitors in patients with oncogene-driven non-small cell lung cancer. Cancer 2019;125:1038-49.

15. D'Incecco A, Andreozzi M, Ludovini V, et al. PD-1 and PD-L1 expression in molecularly selected non-small-cell lung cancer patients. Br J Cancer 2015;112:95-102.

16. Lin C, Chen X, Li M, et al. Programmed DeathLigand 1 Expression Predicts Tyrosine Kinase Inhibitor Response and Better Prognosis in a Cohort of Patients With Epidermal Growth Factor Receptor MutationPositive Lung Adenocarcinoma. Clin Lung Cancer 2015;16:e25-35.

17. Tang Y, Fang W, Zhang Y, et al. The association between PD-L1 and EGFR status and the prognostic value of PDL1 in advanced non-small cell lung cancer patients treated with EGFR-TKIs. Oncotarget 2015;6:14209-19.

18. Soo RA, Kim HR, Asuncion BR, et al. Significance of immune checkpoint proteins in EGFR-mutant non-small cell lung cancer. Lung Cancer 2017;105:17-22.

19. Su S, Dong ZY, Xie Z, et al. Strong Programmed Death Ligand 1 Expression Predicts Poor Response and De Novo Resistance to EGFR Tyrosine Kinase Inhibitors Among NSCLC Patients with EGFR Mutation. J Thorac Oncol 2018;13:1668-75.

20. Cho JH, Zhou W, Choi Y-L, et al. Retrospective Molecular Epidemiology Study of PD-L1 Expression in Patients with EGFR-Mutant Non-small Cell Lung Cancer. Cancer Res Treat 2018;50:95-102.

21. Matsumoto Y, Sawa K, Fukui M, et al. Impact of tumor microenvironment on the efficacy of epidermal growth factor receptor-tyrosine kinase inhibitors in patients with EGFR-mutant non-small cell lung cancer. Cancer Sci 2019;110:3244-54.

22. Lisberg A, Cummings A, Goldman JW, et al. A Phase II Study of Pembrolizumab in EGFR-Mutant, PD-L1+, Tyrosine Kinase Inhibitor Naïve Patients With Advanced NSCLC. J Thorac Oncol 2018;13:1138-45. 